\title{
التفكير الإبداعي في المناهج الدراسية \\ لمقررات الفقه وأصوله 1
}





إن واقع المسلمين اليوم تواجهه تحديات كبيرة ومعضلات متعددة، والنوازل الحادثة في المجتمع أكثر






والمستجدات التي تطرأ في مجتمعه، فيكون قادرا على النظر فيها بما يتوافق وقواعد الشريعة الإسلامية ولأن الظواهر معقدة، والنوازل عديدة متشابكة، فإنه يجدر بنا التعمق في النظر واستثارة تفكيرنا لإيجاد حلول لهذه














الوضوء وصفة بطاقة الائتمان الجائزة.... وهنا لا يمكننا إلقاء اللوم على السابقين من فقهائنا -عليهم رحمة الله- الذين عاشوا زمافمه،




بمحاكاتنا طريقة تأليفهم ومعالجتهم لمسائل زماغم، كما هو شأنسا لئا اليوم عند محاكاتنا المناهج الدراسية الغربية. وإن المتأمل في واقع الدراسات الإسلامية ومناهجها الدراسية اليوم، ووسائلها التعليمية، ومساقاتما،



drfaridazouzou@hotmail.com. كلية الشريعة والقانون، جامعة العلوم الإسلامية بماليزيا 1 أصل هذا البحث ورقة بحثية ألقيت في المؤتمر الدولي: (الإسلام والمسلمون في القرن الواحد والعشرين: الصورة والواقع)، كوالالمبور، مركز بوترا 
ذلك اتجاه الطلاب إلى تلقي الدرس بطريقة مملة، لا توحي في نفس الطالب إلا بالحفظ في الصدور ثم الحفظ في السطور عند التقويم والامتحان، وبذلك تغيب النزعة الإبداعية والتفكير الناقد، الذي يعين على الاستباط والتحليل والنظر في مستجدات الأمور ونوازها، ويغيب عن ذهن الطالب المسلم مبادئ الدرس المرتبطة بالغاية الوجودية للإنسان، في تحقيق العبودية له تبارك وتعالى، ولذا فإن هذه الورقة البحثية تحاول النظر في المناهج






ومستجداته ابتحاها بعيدا عن الحكم الشرعي والنظر الفقهي.






في استخراج الأحكام الشرعية، كما سيظهر خلال البحث. ومن الجدير بالذكر أن تعليم الدراسات والعلوم الإسلامية يستهدف تحقيق أهداف أساسية منها: إيجاد الفرد المسلم الرسالي وإعداده، وتفجير الطاقات الإبداعية في نفس الطالب المسلم، وتطعيم التحفيز





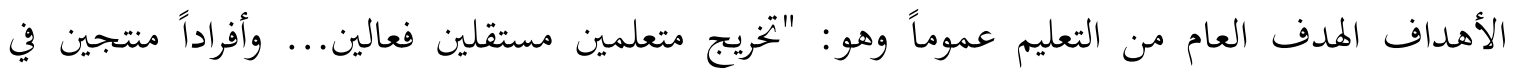



\section{أولاً: طرق التدريس التقليدية والتفكير الإبداعي:}

إن المطلع على المناهج الدراسية للعلوم الإسلامية خصوصاً، والتعليم عموماً، يجد أن الأسلوب النسب




الدراسات. فإن "التعليم عندنا يتمحور حول التلقين والحفظ وشحذ الذاكرة بعيداً عن التفكر والمقارنة الإسيها

22 مسلم، إبراهيم أممد. الجديد في أساليب التعليم: حل المشكلات، تنمية الإبداع، وتسريع التفكير العلمي)، عمان: دار البشير، 1994، 
والتمبيز وتنمية الفكر،"3 ومن خلال تجربتي في التدريس في بلدي الجزائر، وبلدي الثاني ماليزيا، لطلبة








وقتا لتشغيل ذهنه حول استيعاب المادة بطريقة منطقية رياضية، وفي النهاية، وبعد انتهاء الفصل الدراسي


تعاني، لأها تخرج حفظة وملة فقه في الأعم الغالب، ولا تخرج فقهاء ... تخرج نقلة يمارسون عملية الشحن






الطريقة ذاتما وإنما العيب في كيفية استعماها، وتوقيتها، من الملقن والمخاطب؛ فإن كانت طريقة التلقين


الكتب والدفاتر متوافرة إلا بصورة قليلة، فإِها في العصر الحديث -وفي ظل توافر الكتاب الدراسي المقرر


منهجية التدريس في مدارس القرن الواحد والعشرين، من نمط يقوم على الحفظ والاستظهار، إلى نمط مغاير


"تشجيع الطلبة على المشاركة في أهداف الدرس والنشاط، وبعبارة تشجيعهم على تبني أهداف الدرس والأنشطة العلمية."

ويستتبع هذه الطريقة أن المدرسين يسردون المادة العلمية بطريقة جافة غير حيوية، مفرغة من





3 حسنة، عمر عبيد. من مقدمة كتاب التعليم وإشكالية التنمية للدكتور حسن الهنداوي، الدوحة: وزارة الأوقاف والشؤون الإسلامية، (20) 4 حسنة، عمر عبيد. من مقدمة كتاب تكوين الملكة الفقهية للدكتور محمد عثمان شبير، الدوحة: وزارة الأوقاف والشؤون الإسلامية، 1999، صنان. 5 مسلم. الجديد في أساليب التعليم، مرجع سابق، ص142. 
وحضارتنا، وأسلوب حياتنا،" فالبعد الإيماني لكل درس على حدة، له دلالته القوية على ارتباطه بحاجات


إلى معترك الحياة أفراداً فعالين منتجين. إن التعليم في البلاد الإسلامية ليس مجرد مناهج دراسية فصلية أو سنوية، يدخل فيها الطالب البان




حلول لتحديات ومشكلات دخلت إلى عقر دارنا، بل ندرسه لأجل أن يعرف الطالب الطرق الصحيحة






















التعلم تقوده نخو الإبداع بمبادرته للسؤال والمناقشة.


























\section{ثانياً: نحو منهج جديد للتدريس الفعّال:}






























العملية التربوية في مناهج العلوم الإسلامية.

9 8 صديقي، الأسس الإسلامية للعلم، مرجع سابق، ص57.




إذ يُعرِفِ المتخصصون الإبداع بأنه: "المبادرة التي يبذها المرء بقدراته على الخروج والانشقاق من

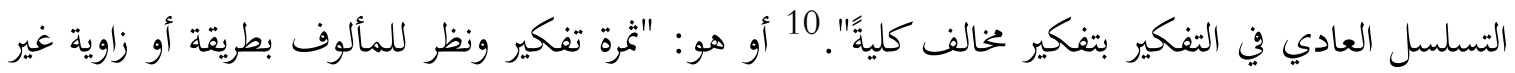






حيث تتجاوز الحفظ والاستظهار إلى التفكير والبحث والتحليل والاستنتاج، ومن ثئَّ الابتكار. 12

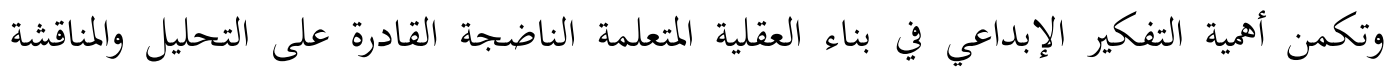






الاجتهاد، من خلال معرفة أسس الاجتهاد والإحاطة التامة بمقاصد الشريعة. وبعبارة أخرى، فإن التفكير الإبداعي الذي نأمله في أساتذتنا ابتداءً وطلبتنا تبعا هو : القدرة على إسلى


منهجية عند الحاجة إليها، ومنها التعامل مع المستجدات والقضايا العصرية.

ثالثاً: مستويات الثفكير الإبداعي في العملية التعليمية: 1- التفكير الإبداعي على مستوى المدرس: فقبل الحديث عن الإبديثي الإبداع في المناهج التعليمية والدراسية، لا بد من الحديث عن ممارس الإبداع، وهو المدرّس، المخطط للمنهج الدراسي وواضعه؛ فلمنهُج







10 المشيقح، عبد الرمن صالخ. الطريق إلى الإبداع، ص22، نقلاً عن صالخ بن درويش حسن معمار، نخو تطوير العمل الإبداعي، ججلة جامعة


11 المرجع السابق، صن3163. 12 الطيطي، محمد حمد عقيل. مهارات التفكير الإيجابي في الممدرسة الأساسية، المؤتمر العلمي العربي الثالث لرعاية الموهوبين والمتفوقين، عمان 
المستوعب لمادة درسه استيعاباً جامعاً شاملاً، في القدرة على المدارسة من المصادر الأصلية وفهمها، وأخيراً

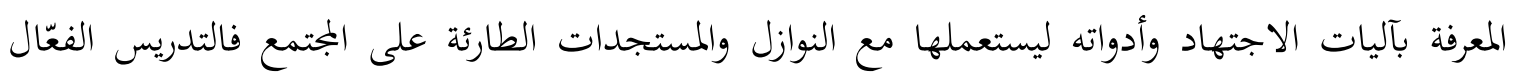











فأما اكتساب المدرس لمهارات التفكير الإبداعي في نفسه ابتداء، فإنه يتأتى من خلال المطالعة



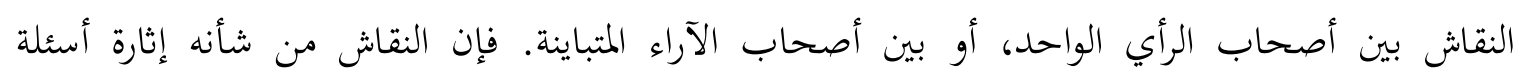






ولكن بصيغ وتعابير جديدة غير مملة. كما يتأتى من خلال إعداد البحوث الأكاديمية والمقالات، سواء أكانت بحوثاً فردية أم جماعية،










عملية تستنهض الأمة.

وكذلك التقويم المستمر، بحيث يعد المدرس خطة عمل فصلية ثم سنوية، يبرمج فيها أهم الأعمال

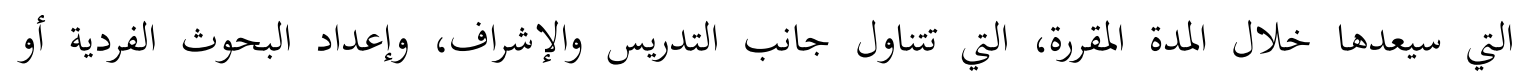



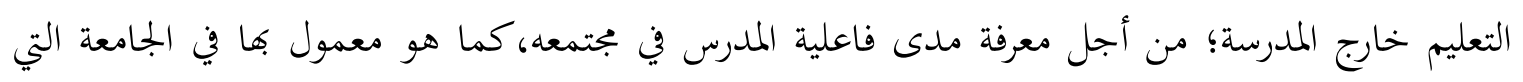






ومعرفة نقط الضعف والقوة، وأسباها، وتعديلها، حتى يسير عمله بصورة منظمة غير خاضعة للظروف

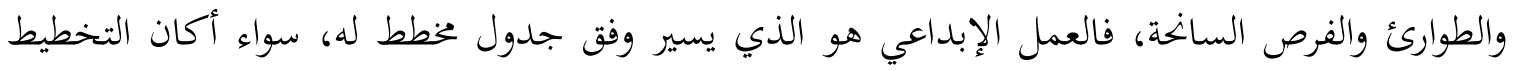
على المدى القريب أم البعيد، فمن شأن التخطيط الذي يسير بجدول العمل نحو التطبيق وتحقيق الأهداف، أن يؤدي إلى الثقة بالنفس، التي تزيد من فاعلية العمل، ومن ثم العمل الإبداعي.




فإن المطلوب من مدرس العلوم الشرعية أن يواكب متغيرات وتحديات عصره الذي يعيشه، فإن التحديات تختلف من عصر لآخر، والمتغيرات الطارئة تتمايز وتتباين، أما منهج التعامل مع هذه التحرية التحديات فيكون باستعمال آلية الاجتهاد، وعلم أصول الفقه الذي يعد المنهج الأساس في التعامل مع نصوص الوحي استخراجا للأحكام الشرعية. وخلاصة لما تقدم قد يلحظ القارئ أنني ركزت على وسائل تنمية الإبداع لدى المعلم، بما يمكن أن








للوقوف في وجه التحديات التي تواجه الإسلام والمسلمين، فإن إعداد الطلبة يكون سهلا! إلماء




المعلم في المدرسة الابتدائية، وبالتالي فإن أهداف المدرسة تختلف عن أهداف الجامعة التي تعد المدرسة الأخيرة، ولأنه: "ينظر إلى مؤسسات التعليم الجامعي باعتبارها المراكز الأساسية للبحث العلمي؛ فالمدرسون

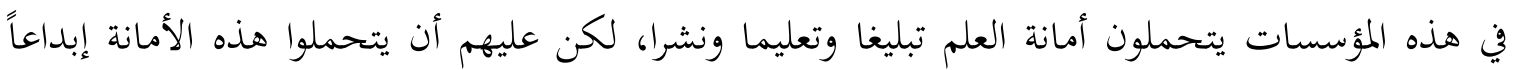




النقاش، وإشراكه في محور الدرس استثارة له نحو التساؤل المجدي.

$$
\text { 13 تراجع هنا كتب: التربية عموماً، وابحاهات التعليه، وفلسفة التربية خصوصاً. }
$$






و نأخذ هنا مثالاً، عند تدريسنا لمادة الفقه المقارن التي لا يحبها أكثر الطلبة، لماذا؟ لأفها تعتمد كثيراً على حفظ الأدلة الكثيرة المختلفة بين المذاهب الفقهية، فهذا المذهب يستند على دليل من الحديث النبوي، والمذهب الآخر يفنده بحديث نبوي آخر، ليجد الطالب نفسه في معركة سيوفها هي نصوص الوحي نفسها.











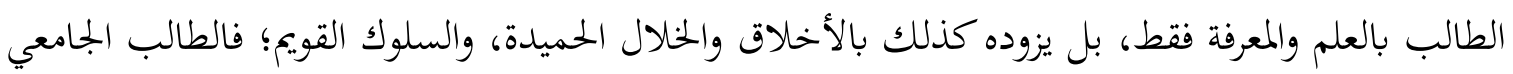

















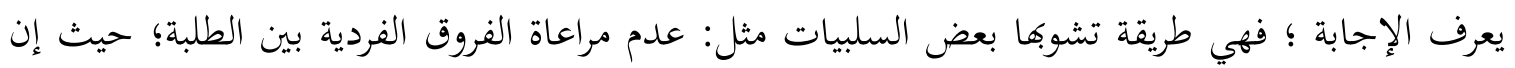

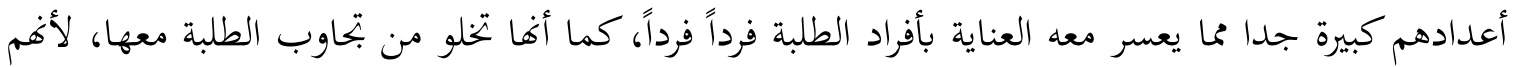
في موقف التلقي فقط، ولم يستثاروا أبدا لسؤال أو حل إشكال إضافة إلى ذلك، فإنها طريقة لا بحذب انتباه







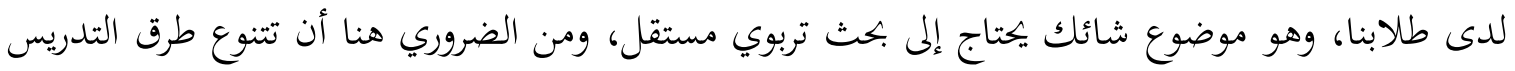








تيسر على المدرس بتميع المعلومات الكثيرة في مساحات قليلة، بطريقة مبسطة جذابة، بتحلب انتباه الطالب كل حين. وتكمن أهمية هذه الوسائل- كما يقول د. أحمد محمد زكي (المتخصص في بجال التقنية): "في استثارة اهتمام التلميذ وإشباع حاجته للتعلم، وتشرك هذه الوسائل جميع حواس المتعلم، مما يؤدي إلى ترسيخ المعلومة، وحسن ترتيب واستمرار أفكار التلميذ، وكذلك تنمي قدرة المتعلم على التأمل ودقة الملاحظة واتباع


ناهيك عن تسهيلها استيعاب الدرس، الذي يتيسر فيه الشرح باستخدام الصور كما في: مناسك


هذا المساق مثلاً وهو ينظر في الخريطة إلى طول المسافة بين مكة والمدينة المنورة، طريق هجرة الرسول يسهل عليه تصور الدرس وفهمه واستيعابه، كما يمكن أن تسهم تقنية المعلومات في حساب مقادير الزكوات، خاصة الحديثة منها؛ مثل أنصبة الأسهم، والسندات، وعروض التجارة عموماً، بطريقة حسابية ميسرة، ومثلها أنصبة الورثة في علم المواريث وغيرها.

واللجوء إلى المناقشة، من الطرق المفضلة لتدريس مجموعات وفرق صغيرة من الطلبة عددهم بين

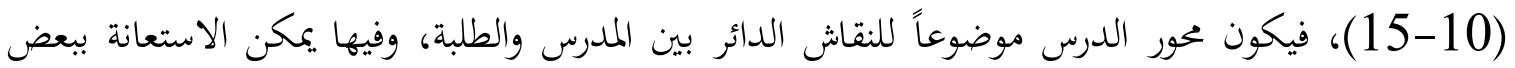
الكتب الجانبية، المساعدة على استثارة التفكير والتساؤل عند الطالب، وهي طريقة تعين كذلك على فهم الموضوع من طرق متعددة، وبالتالي تنمية قدرة الطالب على استيعاب الدرس من أحد الطرق الميسرة عنده.




بروح الدعابة والمرح أحيانا، بإلقاء مزحة يكسر بها صمت الطلبة وهدوههم، كما ينبغي كل حين التنبيه إلى

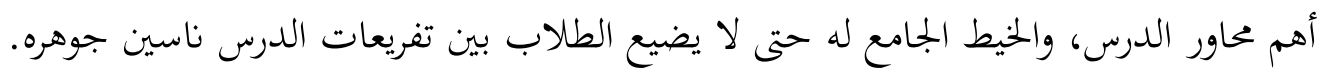

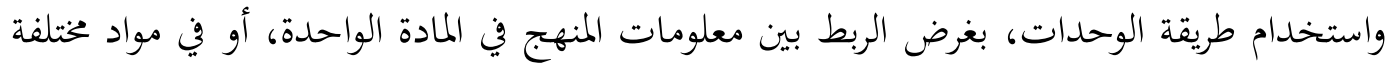
متعددة، حول هدف نظري واحد؛ فالزكاة مثلاً- إذا درست على منهج المواد المنفصلة- تدرس دراسة جافة


ابتحاهات أقوى حيوية وأعظم تأثيرا، مثل: الزكاة ومشكلة الفقر، الزكاة والتنظيم الاقتصادي، الزكاة والتعاون،










كما أنه لا بد من ملاحظة أثر التمثيل بحيثيات ومستجدات الواقع المعيش، فحركة المجتمع، والواقع

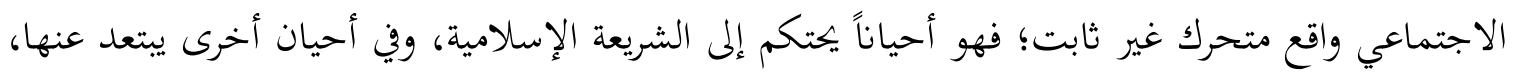

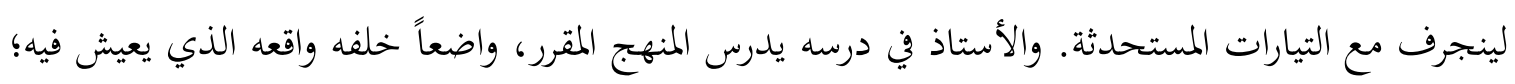

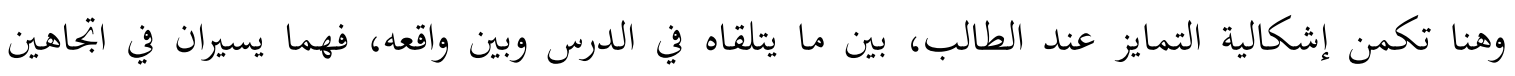


تحقيق مناطها؛ حيث يعد الواقع أحد عناصر تحليل وتحقيق مناطات الأحكام. ومحاولة الاستفادة من العلوم








عزل الطالب عن واقعه الذي يعيشه، خاصة أن مقررات الدراسات الشرعية الحالية تعتمد على التأصيل



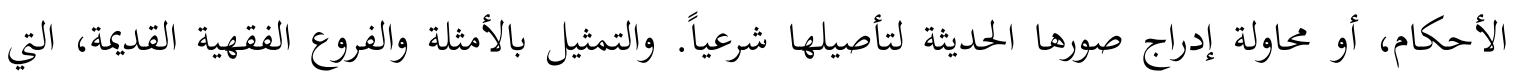




ومن مكامن بحديد الأمثلة بما يناسب العصر إضافة لما سبق، التطرق إليه من بعض الأمثلة في الفقه

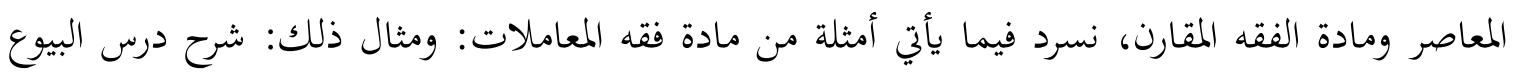













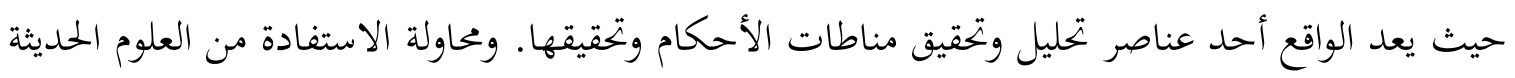

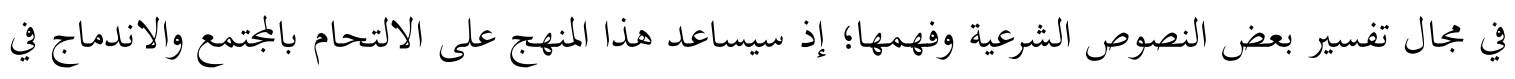

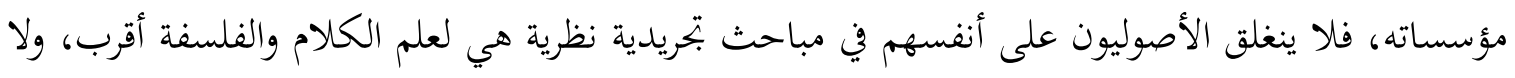




الأمثلة القديمة التي لم ولن تتغير في أي كتاب أصولي قديم أو حديث، وخذ لذلك أمثلة في درس "السبب": القتل العمد سبب لوجوب القصاص، وفي درس "الإجماع"، من الإجماعات إعطاء الجلدة السدس، وفي درس " الرخصة والعزيمة": من أمثلة إباحة ترك الواجب: الفطر في رمضان للمسافر، وغيرها. ومن هنا تظهر أهمية مراجعة المقررات الدراسية لعلم أصول الفقه ومفرداتا، بما جدّ في الواقع من مسائل، لمواجهة التحديات

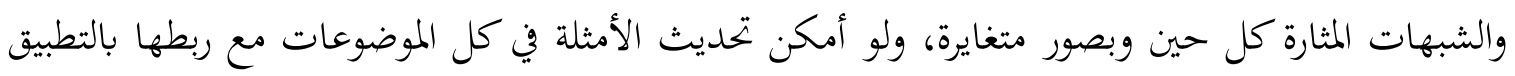
القضائي المعاصر. ومن أمثلة مادة "القواعد الفقهية"، التي تعد من أجل العلوم التي أبدع فيها علماؤنا أهميتها، كما قال

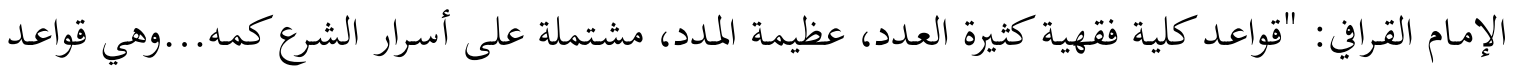

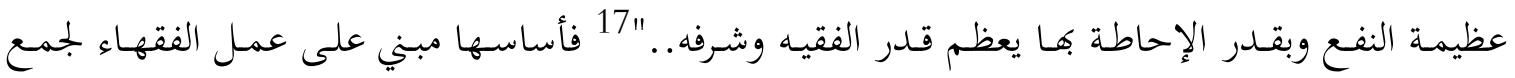

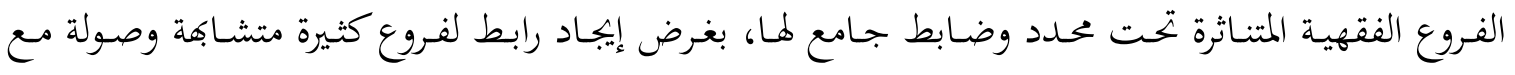



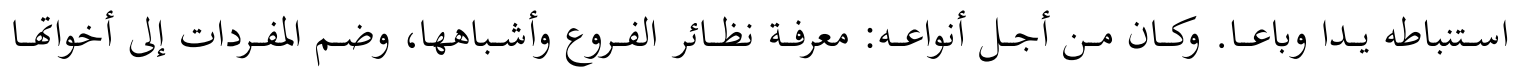





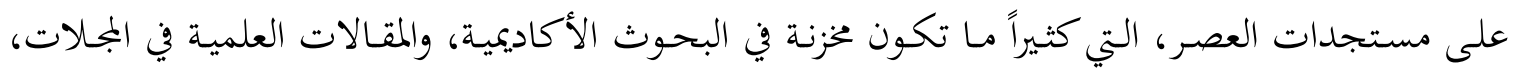


الأستاذ نفسه بدل أن يشرح القاعدة الفقهية الأم، يشرح الأمثلة المستعصية على أذهان الطبان الطلبة، لأفها أمثلة






فالمدرسون لا يبذلون الجهد الكافي في البحث والاستقصاء عن تطبيقات عملية لموادهم، لأفهم هم



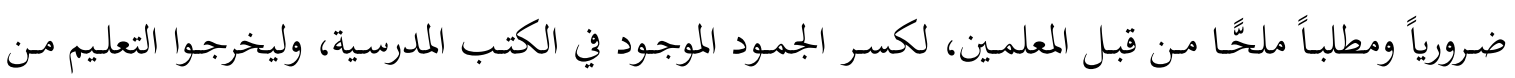

$$
\begin{aligned}
& 17 \text { 18 القرافي، شهاب الدين. الفروق، بيروت: دار المعرفة، د.ت، ج1، ص3. }
\end{aligned}
$$




الحفظ والاستذكار إلى الإقناع والتطبيق. 19 ومن هنا تظهر أهمية مراجعة المقررات الدراسية ومفرداقا بما جدّ

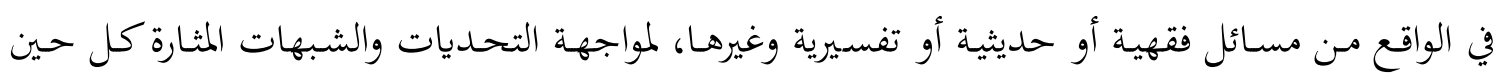

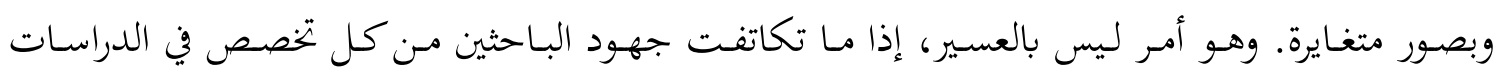


والتفسير المقاصدي للآيات والأحاديث الشريفة، وهو مما سيساعد على تنمية البحث العلمي وتطوير مناهج تدريس الدراسات الشرعية في جوانب تتعدد تعدد الاستقراء المبحوث عنه.







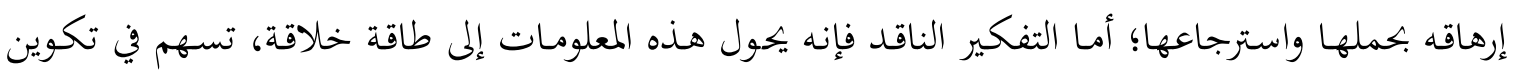



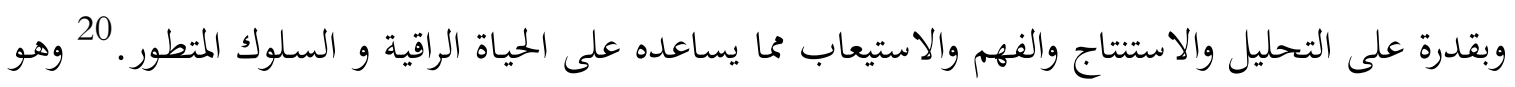



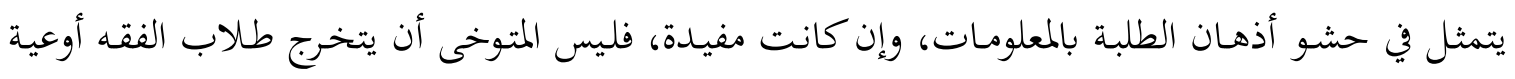

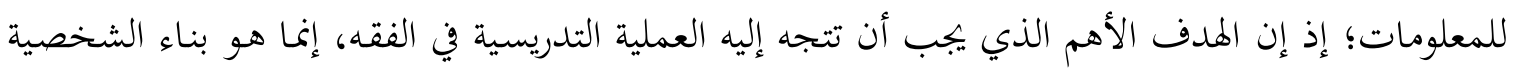







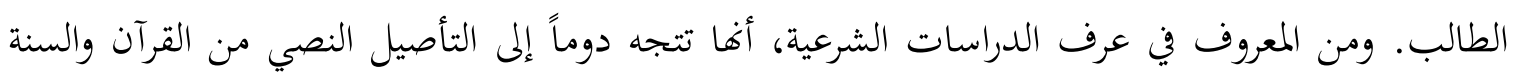







19 أبو عذبة، أيمن. "فليعلموا لماذا يتعلمون: تطبيقات العلوم في الحياة - مادة للطلبة الموهوبين"، المؤتمر العلمي العربي الثالث لرعاية الموهوبين

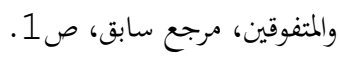



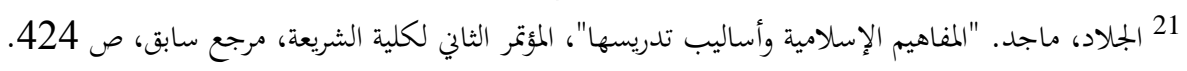

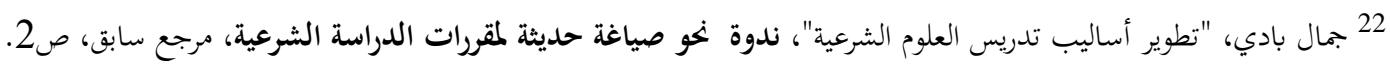


أهم الوسائل المساعدة على إدراك الطلاب فن الإبداع، إكثار المدرس من السؤال، بجيث تكون الأسئلة








استثارة الطلاب، عن طريق طرح بعض التعليقات القصيرة المثيرة، وذلك من أجل استدعاء الآراء والأفكار


صباً، وإنما بتوجيه الطلاب نحو المعلومات، والاشراف على توجيهم الوجهة الصحيحة، وتدريبهم على روح التساؤل، وتشجيعهم على ذلك؛ أي أن يتم عرض الموضوع على هيئة مشكلة أو تساؤل يثير اهتمام التلاميذ

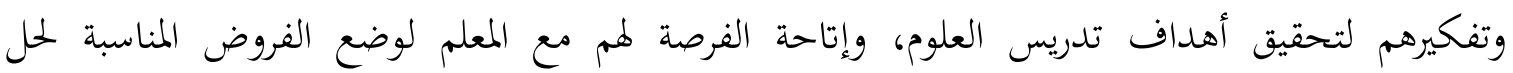


ومن أجل تأهيل الطالب عملياً، يأخذ المدرس في الاعتبار، أن طالب الدراسات الشرعية مثله مثل






يتطلب منه إلماماً بعلوم الشريعة وتفريعاةا؛ فهو سيُسأل كل حين عن مسألة فقهية أو فتوى أو معنى







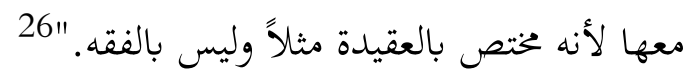


مواد الفقه إلا القليل القليل، حدث أن تزوجت إماما، وهو الأمر الذي استدعى أن كثيراً من نساء المدينة

$$
23
$$






26 حوى، محمد سعيد. "ما الذي نريده من طالب الشريعة فقهاً"، المؤتمر الثاني لكلية الشريعة، مرجع سابق، ص114. 
يزرغا، بغرض الاستفتاء والسؤال، فتجد نفسها حائرة لا تعرف ماذا تقول، والسبب أفا خريجة كلية الدعوة

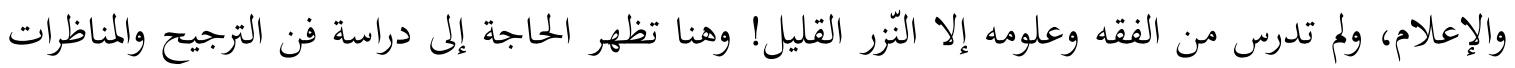
والجدل العلمي، التي حفل بها تاريخنا الإسلامي، فندرب الطلبة على فن المناظرات والاستدلال المقابل للاستدلال المضاد، فإن هذا الفن معناه وجوب استحضار الحكم ودليله بصورة آنية، وذلك يتطلب حفظها هنيا

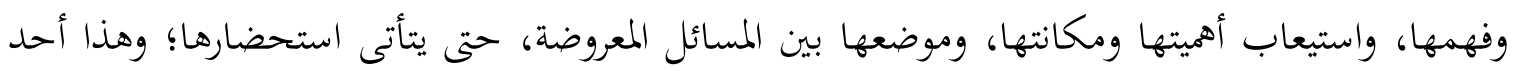
فنون التفكير الإبداعي الذي يتدرب الطلاب عليه في الدرس النظري ثم التطبيقي. فهذه العلوم تعد أعمالاً

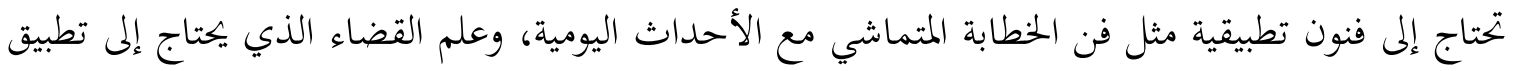
وتمثيل للمحاكم، وبجالس القضاء التي تحتاج معرفة فن الترافع ومحاججة الخصم بالحجة والبيان ... الخ.

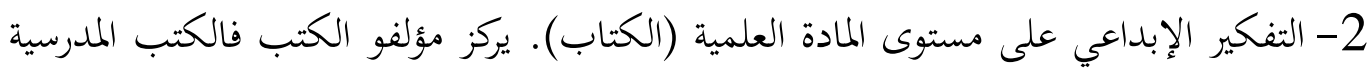

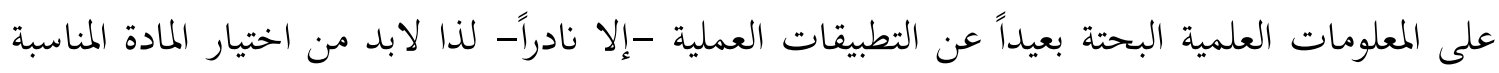





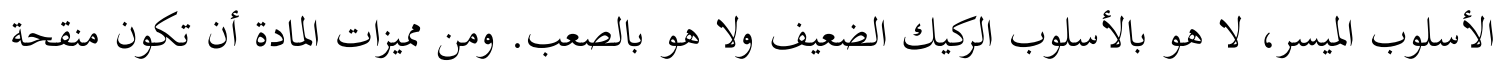









$$
\text { الحديث عادة ما يستند إلى مذهب واحد إما الشافعي أو الحنفي أو غيرهما. }
$$











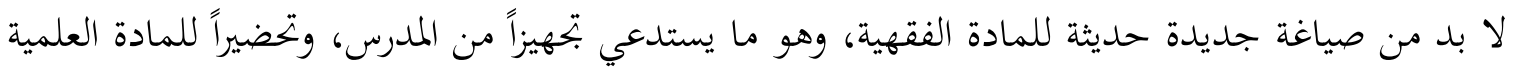

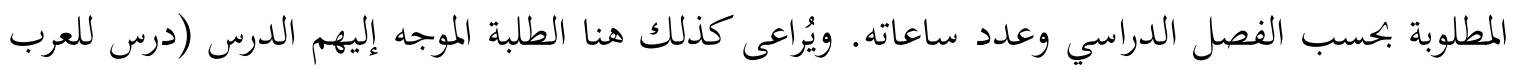

$$
27 \text { الزحيلي، وهبة. الكتاب الفقهي الجامعي: الواقع والطموح، المؤتمر الثاني لكلية الشريعة، مرجع سابق، ص242. }
$$


فقط، للمالويين فقط، لمتعددي الجنسيات)، وهذا فن لا يتقنه إلا مدرس حاذق ماهر . والذي أميل إليه أن

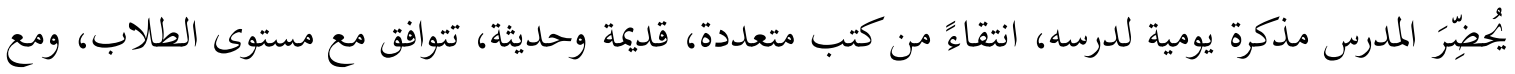
طريقة المدرس نفسه في الدرس؛ وإلا من أين يتأتى الإبداع إذا اعتمد كل مدرس على كتاب واحد مقرر لفصول دراسية كثيرة ولسنوات طويلة؟ فعلى حسب مستوى طلاب كل فصل دراسي يتحدد محتوى

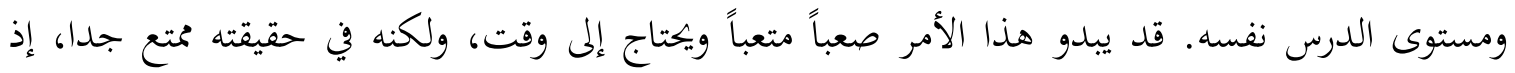

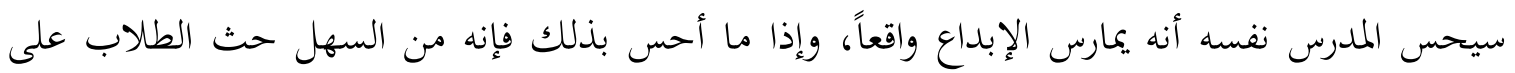
عملية التفكير والإبداع.

ففي فقه العبادات مثلاً، وجب الأخذ في الاعتبار توقيت الصلوات والصيام للذين يقطنون القطب

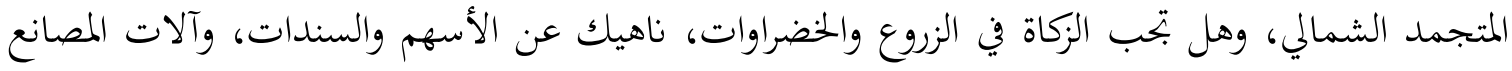

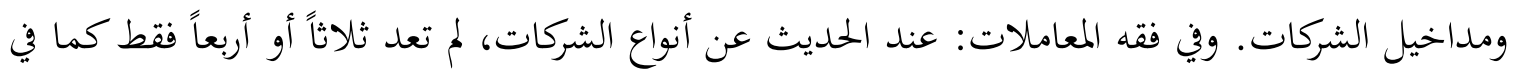

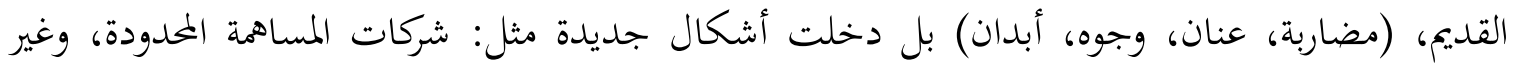
المحدودة، وغيرها؛ كذلك تغيرت في العصر الحديث صور القبض، فلم يعد متمثلاً في القبض باليد فقط بل

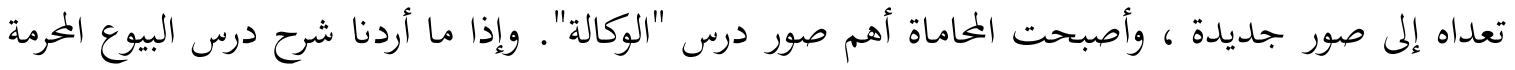

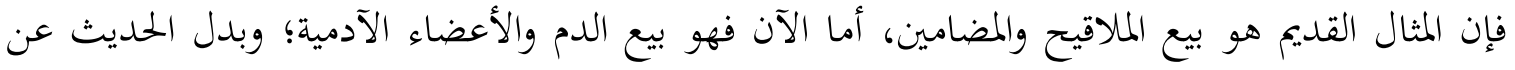

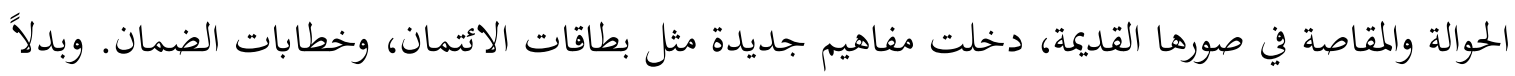
عن الاستدخال، وهو الصورة البدائية في إنجاب الأولاد، أصبح الحديث عن التهديثة التلقيح الاصطناعي بأنواعه المتمثلة في (التلقيح المجهري، وأطفال الأنابيب، والرحم المستأجر) والاستنساخ.

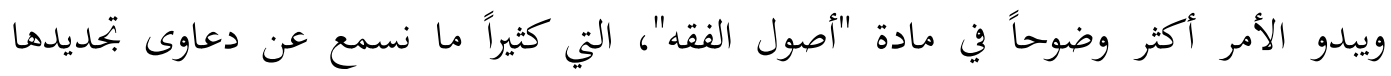

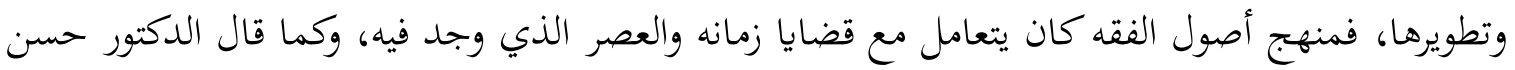

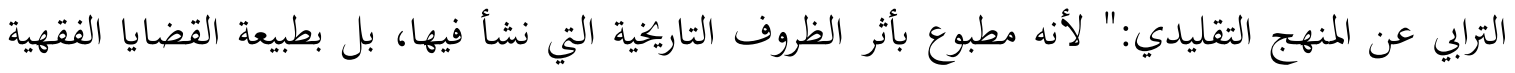

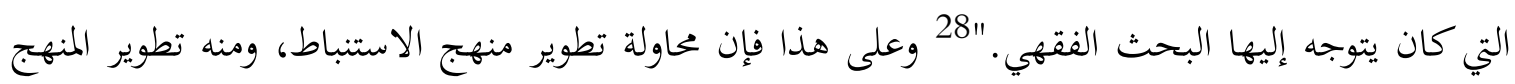

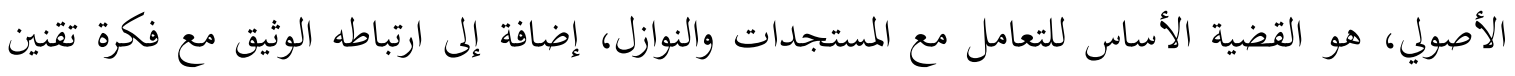

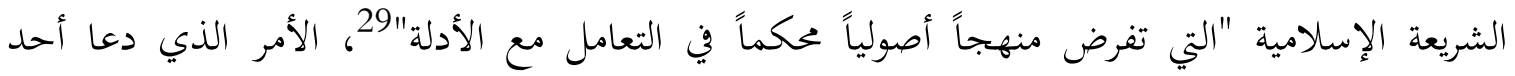

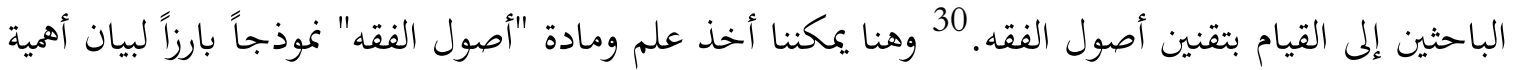

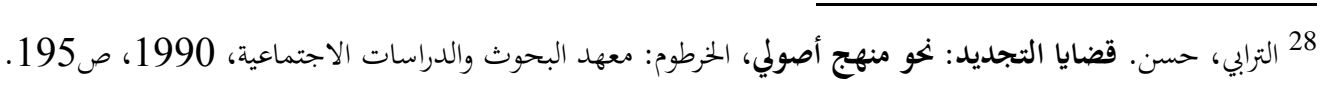

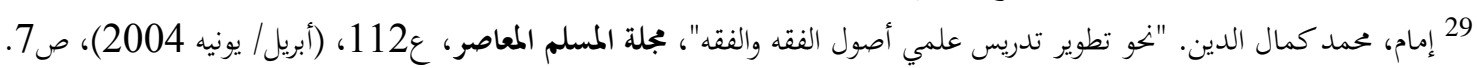

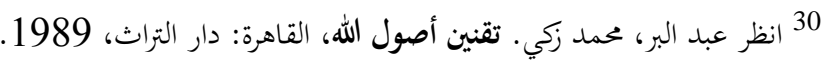


التحلي بالنظرة النقدية الإبداعية، بغرض أن يكون الدرس الأصولي مستوفياً لقواعد استباط الأحكام

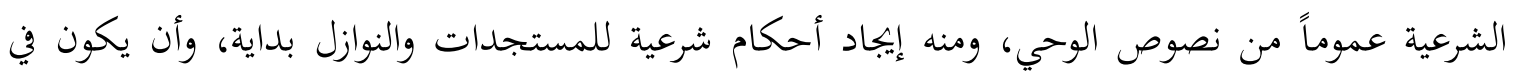
مستوى الطلبة بإعانتهم على اكتساب ملكة الاستنباط من الأدلة فاية.

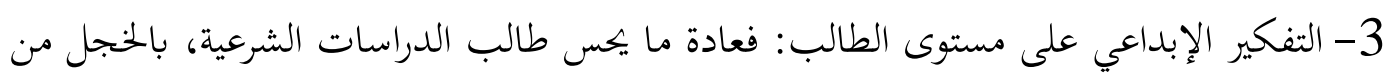

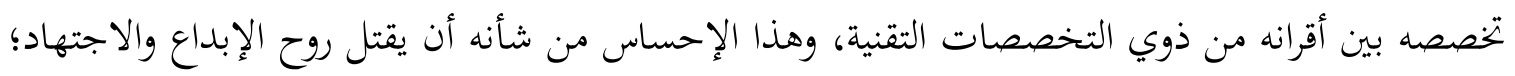

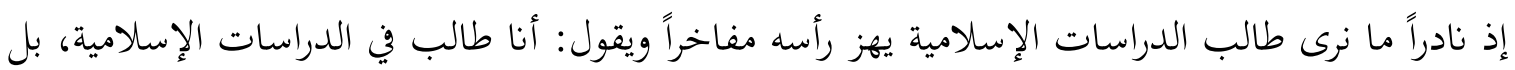
يقولما على استحياء؛ رغم أن هذا التخصص وهذا العلم من أشرف العلوم وأقصرها طريقا للوصول لمرضاة الله

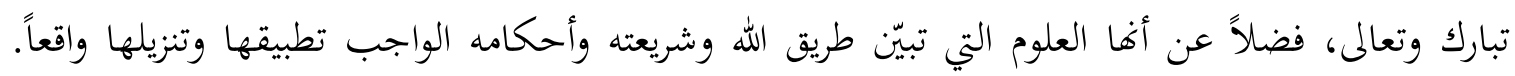

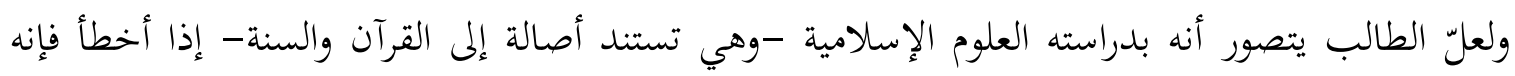

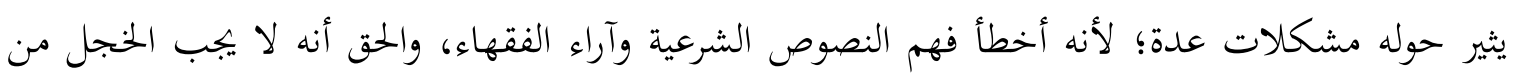

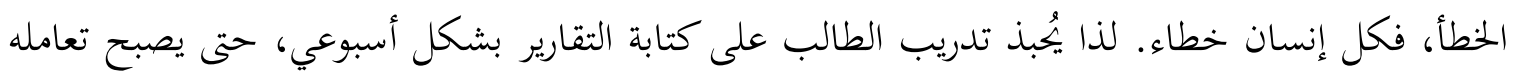

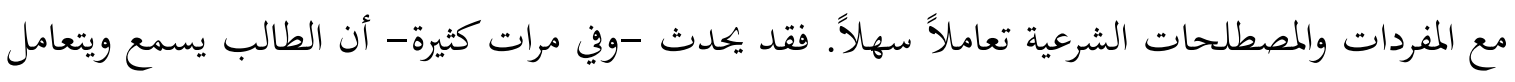

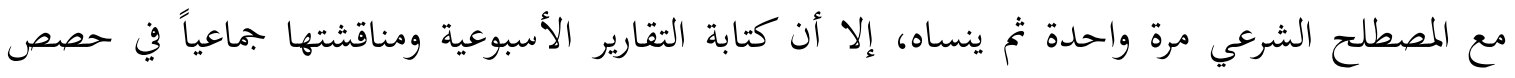

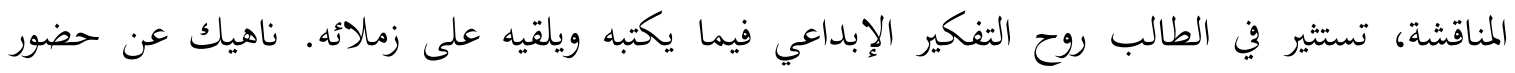

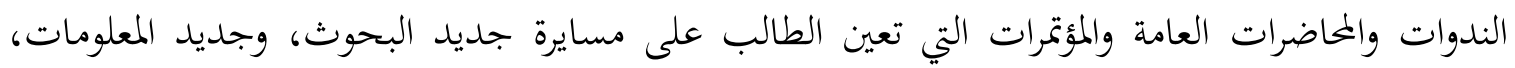

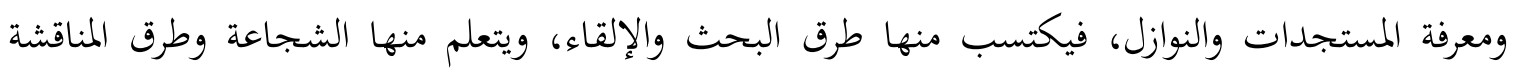
والسؤال والتعقيب والاستدراك وغيرها من طرق وأساليب الحوار والنقاش المجدي.

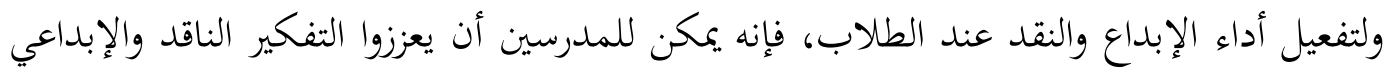

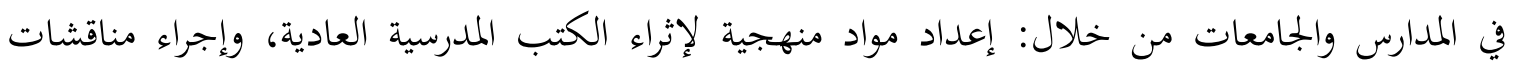
وحوارات حول قضايا خلافية، وحث الطلبة على القيام بأداء الأدوار حول أحداث تاريخية؛ حيث تنتبنى

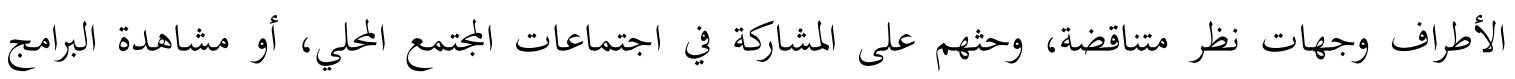

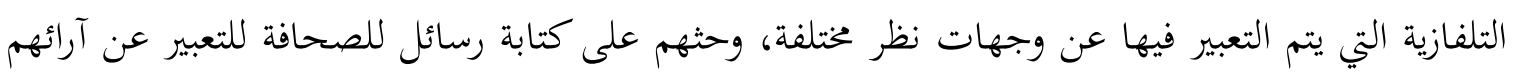
حول قضية محلية معاصرة، وتشجيعهم على أن يُحلّلوا مقالات صحفية ومواد أخرى لإيجاد أمثلة على التحيّز

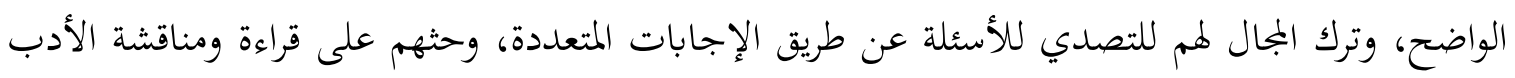


الذي يعكس قيماً وتقاليد مختلفة عن تلك التي يتبنوها، ودعوة أشخاصٍ لهم وجهات نظر خلافية ليتحدّثوا مع الطلبة.

وأؤكد هنا أن: الطالب المبدع لا يوجد من فراغ بل من توافر مدرس مبدع فعال، ومادة تعليمية إبداعية، ووسائل تدريسية ناقدة وبناءة وفعالة. وهذه هي شروط التدريس من أجل التفكير الإبداعي: المدرس المبدع والمادة البناءة والطالب المجدّ.

ثالثاً: لمحات إبداعية في دعاوى تجديد منهج أصول الفقه:

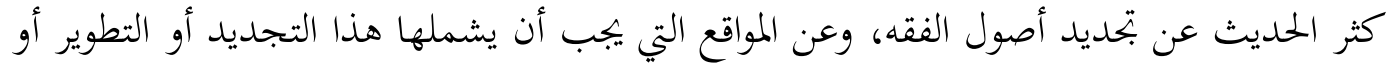
التنقيح أو الإلغاء. فلم يعد أصول الفقه هو "بجموع طرق الفقه على سبيل الإجمال، وكيفية الاستدلال بها، وكيفية حال المستدل."

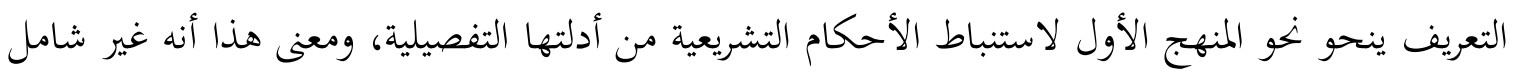

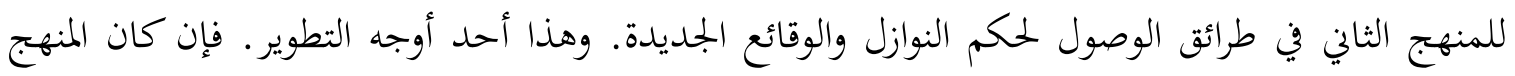

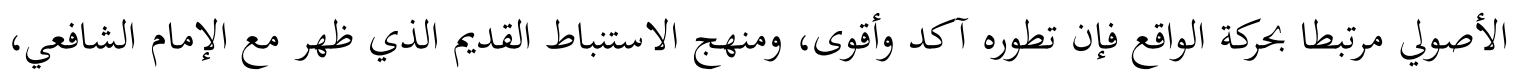

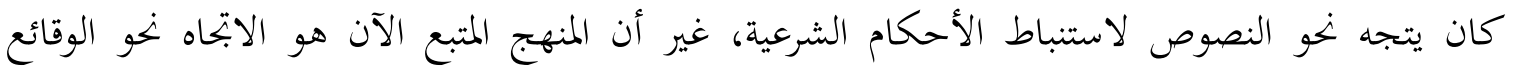
والنوازل والنظر في النصوص للبحث عن أحكام. ومن أوجه التجديد التي يمكن طرحها:

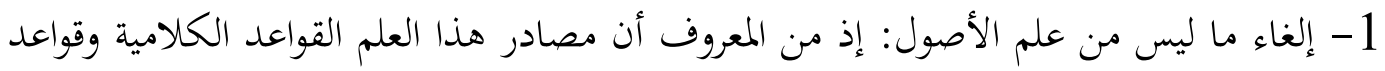

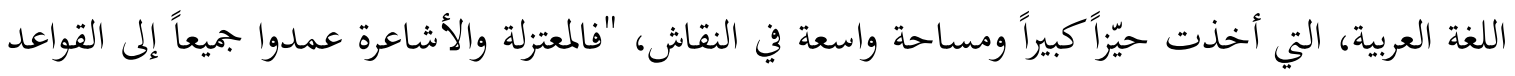

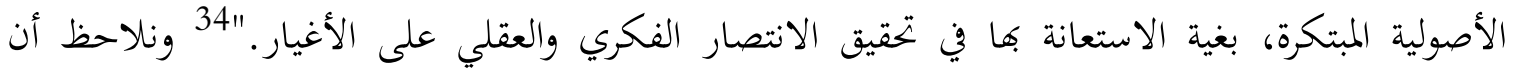

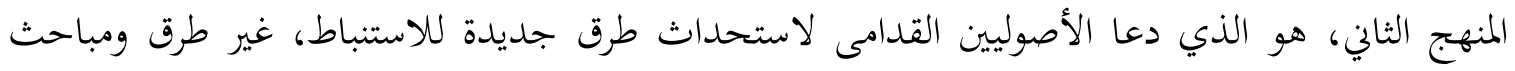
علم الكلام والمباحث اللغوية مثل: مباحث الاستحسان، وسد الذرائع، والمصالح المرسلة، وغيرها مما يجب ملاحظته. 2- تطوير وضبط مفاهيم بعض الأدلة: ومن أمثلة ذلك مبحث الإجماع الذي تبدأ إشكاليته من التعريف ذاته. ومبحث الاجتهاد وشروطه التعجيزية التي تكون بحق سبب دعوى غلق التهن باب الاجتهاد.

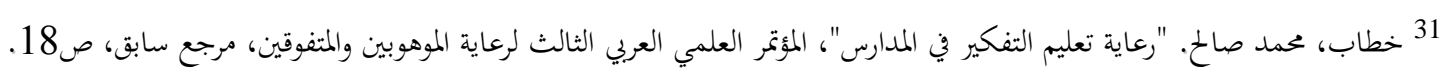

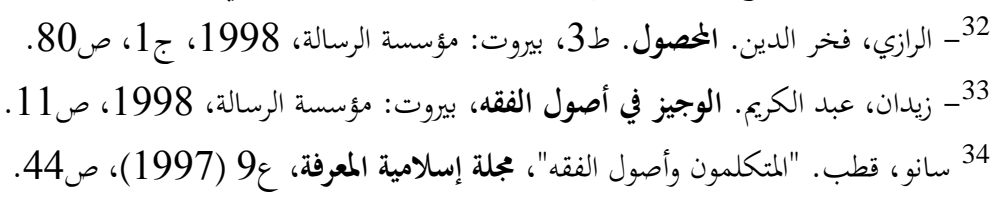


والدعوة إلى اعتماد الاجتهاد الجماعي، وغيرها من المسائل التي تتتاج إلى تفصيل كثير لا يسعه هذا المقام، وهو مما يمتاج إلى دراسات معمقة.

3- تدريس المقاصد الشرعية بصورة وافية: فإن الطرق القديمة لم تعد تؤدي بالغرض في استنباط

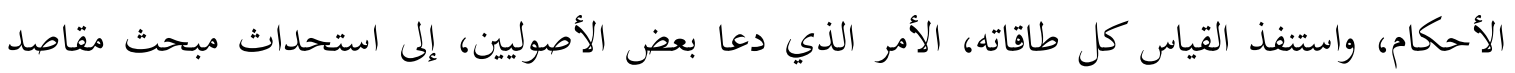
الشريعة، للنظر في نصوص الشريعة وفق إطار عام ضابط للنظر الاجتهادي، هو إطار مقاصد الشارع

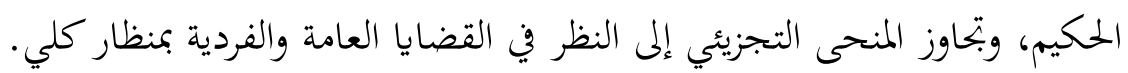
فهذا الجويني -من خلال النظر في نظرية الضرورة عند الفقهاء، والتي تقوم على آحاد الأفراداستكشف ضرورة الجماعات في تخمينه الواقع على (خلو الزمان من الفقهاء)، التي تمثلت في الضروريات الخمس. فقد ابتكر الإمام الجويني رممه الله التقسيم الثلاثي لمقاصد الشريعة باعتبار آثارها في قيام المجتمع إلى:

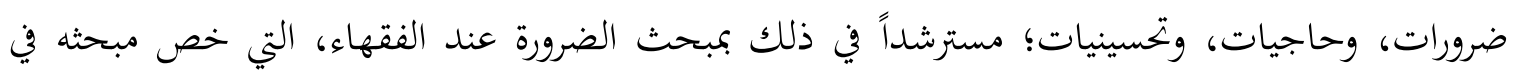

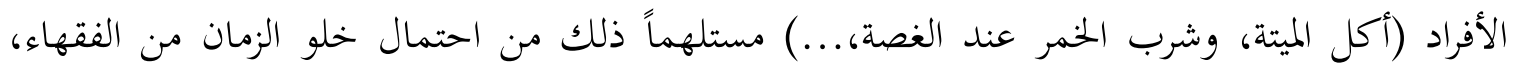
فكيف يعرف العامي الحلال من الحرام. أما الإمام الغزالي رحمه الله فقد طوّر ما وصل إليه شيخه الجويني، ولم يحصره في فرض احتمال خلو

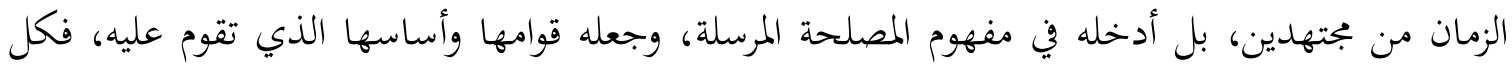

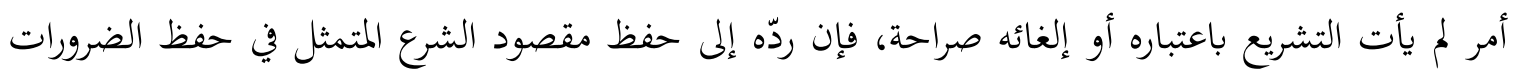

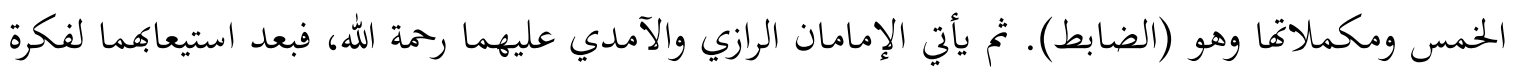

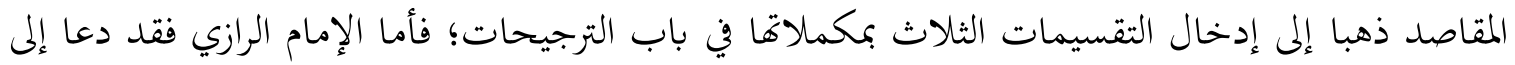

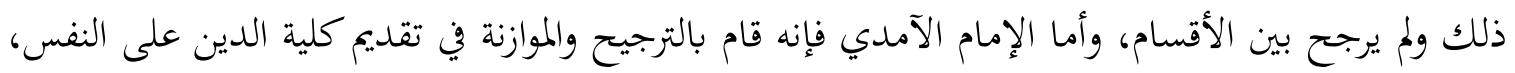

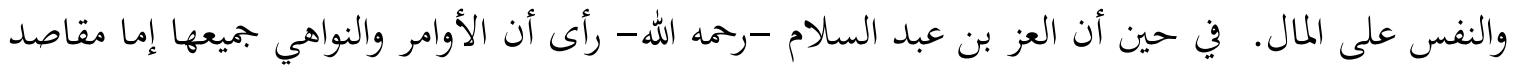

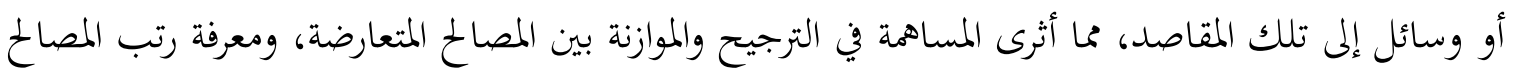
والمفاسد. تم يأتي الإمام الشاطبي، الذي لم يترك فكرة المقاصد كما هي عند سابقيه، جزءًا صغيراً في مبحث

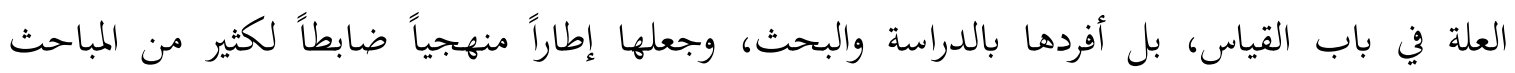

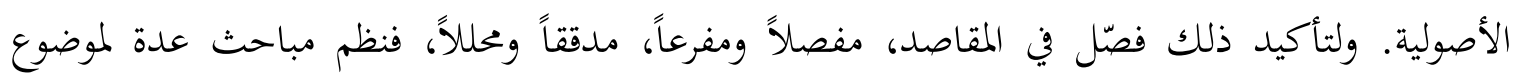
المقاصد، مطوراً فكرة الوسائل وعملية الحفظ. وفي محاولة درء التعارض بين آحاد النصوص استكشف مئف الشاطبي كليات النصوص، والانتقال من النظر الجزئي إلى الكلي، وهو الذي أبدع في في المسالك التي أعدّها 
للكشف عن المقاصد، التي تنطلق من النظر في آحاد النصوص لتصل إلى الكليات والعمومات التي تحويها وتتضمنها نصوص الوحي. 35 ويف العصر الحديث نجد ابن عاشور يحمل ذلك الميراث المقاصدي، ويسير على خطا الشاطبي في

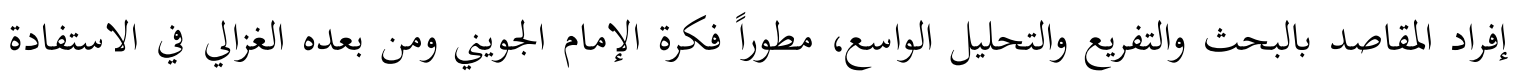

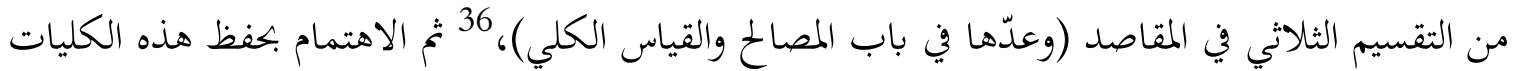

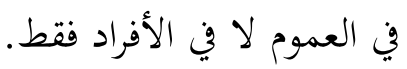
و يأتي الآن دور الباحثين في تطوير مقاصد الشريعة وجعلها الإطار العام للدراسات الأصولية؛ "فإن المنهج الأصولي لا تتوافر فيه كل الخصائص العلمية للاستنباط الفقهي؛ إلا إذا أخذت دراسة المقاصد حظها

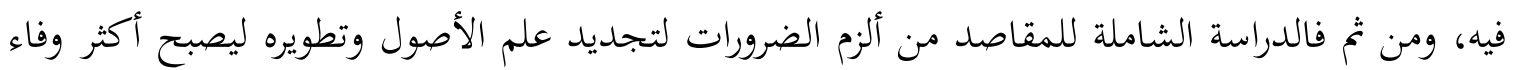

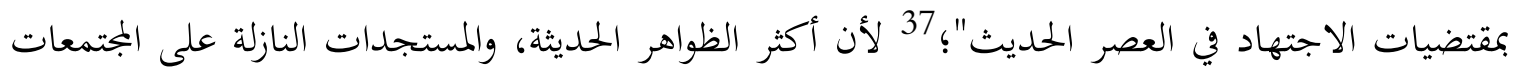

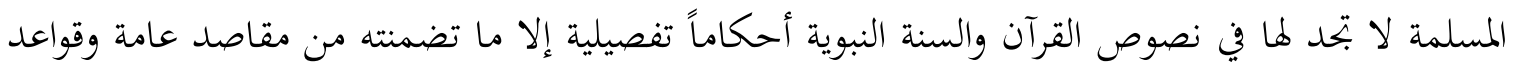

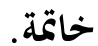

وفي ختام هذه الورقة البحثية أود أن أبيّن آفاق هذه الدراسة وهي أن يُراعى عند تدريس العلوم الإسلامية،

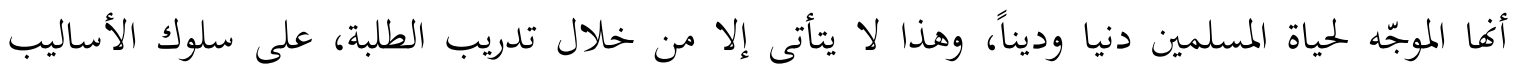

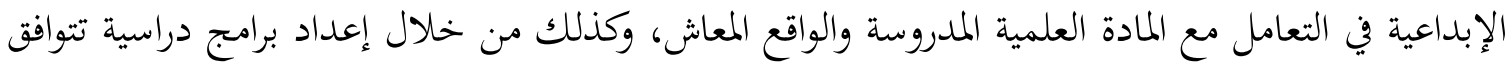

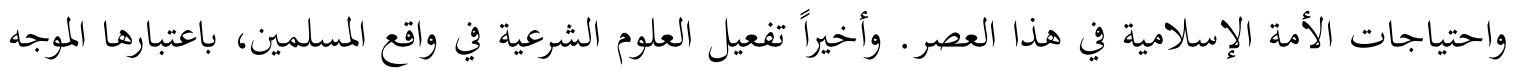
ابتداءً، وآلية التطور والنهضة باتلمجتمع تبعاً.

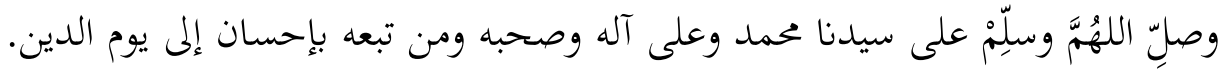

35 زوزو، فريدة. النسل: دراسة مقاصدية في وسائل حفظه في ضوء تحديات الواقع المعاصر، الرياض: دار الرشد، 2004، ص29 وما بعدها.

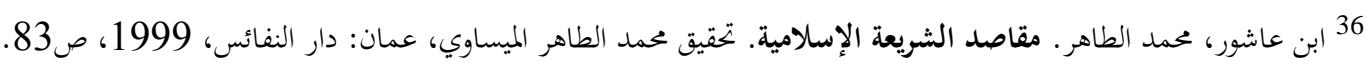

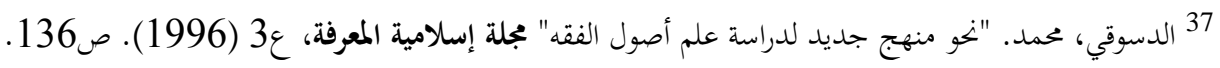

